\title{
AVALIAÇ̃̃o DAS VARIÁVEIS ANALÍTICAS DO MÉTODO DE FOLIN-CIOCALTEU PARA DETERMINAÇÃo DO TEOR DE TANINOS TOTAIS UTILIZANDO COMO MODELO O EXTRATO AQUOSO DE FOLHAS DE Psidium guajava $\mathbf{L}$.
}

Simone Gasparin Verza, Maria T. Kreinecker, Valquíria Reis, Amélia T. Henriques e George González Ortega*

Faculdade de Farmácia, Universidade Federal do Rio Grande do Sul, Av. Ipiranga, 2752, 90610-000 Porto Alegre - RS, Brasil

Recebido em 14/3/06; aceito em 24/8/06; publicado na web em 26/3/07

\begin{abstract}
EVALUATION OF ANALYTICAL VARIABLES OF THE FOLIN-CIOCALTEU METHOD FOR THE QUANTITATION OF THE TOTAL TANNINS CONTENT USING A Psidium guajava L. LEAVES AQUEOUS EXTRACT AS A MODEL. The main analytical variables of a modified Folin-Ciocalteu method were studied by UV-Vis and gradient HPLC-PDA methods, using purified (PC) and technical grade (TGC) casein. Rutin and an aqueous extract of Psidium guajava L. leaves were used as models. The best results were ascribed to TGC. Certainly PC bonds the polyphenols of the $P$. guajava extract better than TGC, but TGC afforded better precision. A lack of specificity occurred when rutin was analyzed together with the $P$ guajava extract. Additional analyses performed with the flavonoid fraction of $P$. guajava extract by HPLC-PDA had confirmed that casein was able to bind catechin, gallic acid and $P$. guajava flavonoids in a non-specific way.
\end{abstract}

Keywords: tannins; casein; hide powder.

\section{INTRODUÇÃO}

Atualmente, os principais métodos para determinação do teor de taninos abrangem a cromatografia líquida de alta eficiência (CLAE) e a espectrofotometria. Os métodos espectrofotométricos mais aceitos envolvem a complexação prévia dos taninos com substratos protéicos (pó-de-pele, caseína, albumina) ou poliméricos (PVPP). Em todas as suas variantes, os métodos por oxi-redução derivam, basicamente, da proposta de quantificação do ácido úrico por Folin e Macallum¹, mais tarde modificado para polifenóis ${ }^{2}$. Nestes, os polifenóis reagem com reagentes de oxi-redução específicos, formando um complexo de coloração azul, passível de ser quantificado por espectrofotometria no visível. Conseqüentemente, a reação não é específica para taninos. Uma forma de contornar essa falta de especificidade é retirando os taninos do meio mediante adsorção com substratos protéicos. Assim, o teor de taninos é calculado como a diferença entre o teor de polifenóis totais e teor da fração polifenólica não-adsorvida ${ }^{3-5}$.

Vários métodos espectrofotométricos atualmente aplicados a drogas vegetais foram desenvolvidos em um marco regulatório diferente do atual, tendo-se desenvolvido a partir do reagente de Folin e Macallum. Diferentes Farmacopéias e Códigos Oficiais determinam condições de análise distintas ao longo dos anos. Isso não necessariamente parece ter implicado a validação específica dos mesmos como métodos gerais ou específicos. Isso inclui o método de determinação do teor de taninos totais, baseado no uso de póde-pele e caseína como agentes complexantes. No presente trabalho, foram avaliadas as principais variáveis analíticas, com ênfase na especificidade da caseína frente à presença simultânea de flavonóides no meio reacional. Com esse intuito, rutina e Psidium guajava foram selecionados como substância e extrato modelo.

Nos métodos por CLAE o reagente de Folin-Ciocalteu não é utilizado. No entanto, esse tipo de método foi empregado nesse trabalho com fins de caracterização do extrato vegetal de Psidium guajava. A utilização dessa técnica com fins analíticos foi desconsiderada no pre-

*e-mail: ortega@farmacia.ufrgs.br sente trabalho, partindo-se do pressuposto que a quantificação de polifenóis individuais não reflete a parcela polimérica dos taninos.

\section{PARTE EXPERIMENTAL}

\section{Solventes e reagentes}

Foram usados caseína purificada (Sigma, C5890; lote: 042K0112; EUA); caseína grau técnico (CGT) (Sigma, C7870, lote: 35H0822; EUA); pó-de-pele (Freiberg-Forschungsinstitut; Alemanha); pirogalol (Merck; EUA); catequina (Sigma; EUA); rutina (Sigma; EUA); acetonitrila grau HPLC (Merck; EUA); ácido fosfórico 85\% (Merck; EUA).

\section{Material vegetal}

Consistiu de folhas de Psidium guajava L. (Myrtaceae, goiabeira) coletadas no município de Porto Alegre, em março de 2004, secas em estufa de ar circulante, durante 5 dias, a $40{ }^{\circ} \mathrm{C}$, e moídas em moinho de facas $(180 \mu \mathrm{m})$.

\section{Reagente de Folin-Ciocalteu}

Preparado conforme preconizado pela Farmacopéia Européia ${ }^{6}$.

\section{Preparação do extrato vegetal}

A extração foi realizada conforme descrito na referência 6 utilizando-se $0,5 \mathrm{~g}$ de matéria-prima e uma proporção droga solvente de 1:500 (m/m). Em todos os casos, a perda por dessecação foi considerada.

\section{Preparação do produto seco liofilizado}

O extrato vegetal foi submetido a processo de secagem por liofilização, utilizando-se pressão de $10^{-1}$ mbar e temperatura de $-60{ }^{\circ} \mathrm{C}$. 


\section{Determinação dos polifenóis totais}

Foi realizada conforme descrito na referência 6, com modificações. O comprimento de onda de leitura ótimo foi estabelecido mediante varredura na faixa de 400 a $800 \mathrm{~nm}$, em 30 min após a adição do reagente de oxi-redução ao extrato previamente diluído, de modo a obter leituras de absorvância entre 0,4 e 0,8 U.A. O tempo de leitura foi estabelecido mediante acompanhamento da cinética de reação nos tempos de 0,$5 ; 1 ; 2 ; 3 ; 5 ; 10 ; 15 ; 20 ; 30$ e 60 min após a adição do reagente de oxi-redução à solução extrativa diluída, com leitura em $760 \mathrm{~nm}$. A quantidade ótima de agente de oxi-redução, capaz de assegurar a linearidade na faixa de trabalho pretendida, foi determinada mediante análise de regressão das curvas de calibração obtidas para pirogalol $\left(0,8,1,6,2,4,3,2\right.$ e 4,0 $\left.\mu \mathrm{g} \mathrm{mL}^{-1}\right)$. As soluções de compensação (brancos) foram obtidas substituindo-se o volume de amostra por água, mantendo-se as mesmas quantidades de reagente de Folin-Ciocalteu e solução saturada de carbonato de sódio.

\section{Quantificação da fração não-tanante}

Foi realizada segundo descrito na referência 6, utilizando-se concentrações de caseína de 100, 200, 300, 400, 500, 600, 700 e $800 \mathrm{mg}$. Os parâmetros de comprimento de onda de leitura, tempo de leitura e quantidade de reagente de oxi-redução foram os mesmos estabelecidos no item Determinação dos polifenóis totais.

\section{Seleção da substância de referência}

A seleção foi baseada na semelhança entre os espectros de absorção do pirogalol $\left(2,4 \mu \mathrm{g} \mathrm{mL}^{-1}\right)$ e do extrato vegetal $\left(32 \mu \mathrm{g} \mathrm{mL} L^{-1}\right)$ na região de 400 a $800 \mathrm{~nm}$. As condições experimentais para a preparação das soluções de leitura foram as mesmas indicadas no item Determinação dos polifenóis totais.

\section{Curva de calibração do pirogalol (substância de referência)}

As curvas de calibração utilizando 1,0 e $2,0 \mathrm{~mL}$ do reagente de Folin-Ciocalteu foram obtidas para as concentrações de pirogalol de 0,$8 ; 1,6 ; 2,4 ; 3,2$ e $4,0 \mu \mathrm{g} \mathrm{mL}^{-1}$.

\section{Análises por CLAE}

As condições de análise por CLAE foram as seguintes: pré-coluna: Shimadzu $(10$ x $4 \mathrm{~mm})$ com Bondapack $\mathrm{C}_{18} 125 \mu \mathrm{m}$ (Waters, Milford, MA), coluna: Phenomenex Gemini $5 \mu, \mathrm{C} 18,110 \mathrm{~A}$ (250 x 4,60 mm), cromatógrafo Waters 2695 com injetor automático, detector Waters (996) de Photodiode Array (PDA) e software Empower.

A separação foi desenvolvida empregando-se um gradiente, utilizando misturas de ácido fosfórico $0,5 \%$ (solução A) e acetonitrila:ácido fosfórico a 0,5\% $(60: 40 \mathrm{~m} / \mathrm{m})$ (solução B), em diferentes proporções. Fase 1: de 13 a $25 \%$ de B, em 25 min; fase 2: permanecendo em $25 \%$ de B, por 5 min; fase 3: de 25 a $33 \%$ de B, em $7 \mathrm{~min}$; fase 4: permanecendo em $33 \%$ de B por $3 \mathrm{~min}$; fase 5: de 33 a $40 \%$ de B, em 7 min; fase 6: permanecendo em $40 \%$ de B, por 3 min; fase 7: de 40 a $43 \%$ de $\mathrm{B}$, em 3 min; fase 8: permanecendo em $43 \%$ de B, por 2 min; fase 9 (acondicionamento): de 43 a $13 \%$ de B, em 15 min. Fluxo 0,8 mL min ${ }^{-1}$. Detecção em 280 e 352 nm, com sensibilidade de 0,5 U.A.

\section{Preparação de amostras para análise por CLAE}

Para as análises da solução extrativa, $100 \mathrm{mg}$ do produto liofilizado foram diluídos em 50,0 mL de água. Alíquotas de 10,0
$\mathrm{mL}$ da solução foram tratadas com quantidades de 400 a $1600 \mathrm{mg}$ de caseína ou 100 mg de pó-de-pele.

Para as análises das substâncias de referência, preparou-se uma solução constituída de mistura de ácido gálico, catequina, pirogalol e rutina com concentrações individuais de $80 \mu \mathrm{g} \mathrm{mL}$.

\section{Análise estatística}

Nas análises de linearidade foram contemplados os seguintes parâmetros: coeficiente de regressão, teste $\mathrm{F}$, limites de confiança para os coeficientes linear e angular e, análise dos resíduos pelo teste de Durbin-Watson. A comparação entre retas foi realizada considerando-se testes de similaridade para os coeficientes angular e linear ${ }^{7,8}$. Exceto quando estipulado de modo contrário, todos os resultados expressos derivam da média aritmética de pelo menos três medições. Todos os dados foram processados em Excel 2003 (Microsoft Office).

\section{RESULTADOS E DISCUSSÃO}

A revisão comparativa dos métodos gerais de determinação do teor de taninos totais por oxi-redução revelou diversidade de especificações analíticas entre algumas das principais Farmacopéias e Códigos Oficiais ${ }^{6,9,10,11}$. Assim, o comprimento de onda de leitura varia de 730 a $760 \mathrm{~nm}$, dependendo do material vegetal analisado, e os tempos de leitura de 2 para 25 a $30 \mathrm{~min}$. O extrato de folhas de Psidium guajava apresentou absorção máxima em $760 \mathrm{~nm}$, após o tratamento com o reagente de Folin-Ciocalteu. A solução de pirogalol também apresentou um máximo de absorção muito próximo (765 $\mathrm{nm}$ ), quando tratado nas mesmas condições experimentais. Esta proximidade na região de absorção reforçou a seleção do pirogalol para este trabalho, uma substância já descrita para este fim.

As cinéticas de reação do reagente de Folin-Ciocalteu com pirogalol e com o extrato vegetal mostraram comportamentos semelhantes. Em ambos os casos, logo após um breve período de estabilidade, ocorreu uma segunda fase de aumento acentuado, quase-exponencial, que atingiu valores máximos de absorvância 30 min após a adição do reagente. Este resultado coincide com o preconizado por alguns Códigos Oficiais ${ }^{6,9-11}$.

A possibilidade de esgotamento do reagente de oxi-redução em análises de taninos fora anteriormente assinalada por Martins ${ }^{12}$, que constatou a perda da linearidade nas curvas de calibração do pirogalol e de uma solução extrativa de Maytenus ilicifolia. Este fato foi notório para o extrato aquoso de folhas de goiabeira, quando utilizado 1,0 mL de reagente de Folin-Ciocalteu, especificamente nas faixas de maior concentração de analito. A adição de 2,0 $\mathrm{mL}$ restabelece, contudo, a linearidade, a qual se manteve estatisticamente igual quando a quantidade de reagente foi aumentada para 3,0 mL. O mesmo fato foi também observado neste trabalho para o pirogalol, nas faixas de concentração referentes às respectivas curvas de calibração. Isso fica evidente na comparação estatística das equações de regressão e dos respectivos limites de confiança (LC) calculados para as curvas de calibração do pirogalol com 2,0 e 1,0 $\mathrm{mL}$ de reagente (Equações 1 e 2, respectivamente)

$-0,0203+0,2165 \mathrm{x}$

$\left(\mathrm{R}^{2}=0,9982 ; \mathrm{F}=7446,76 ; \mathrm{LC}\right.$ intercepto $=-0,0059:-0,0346 ; \mathrm{LC}$ inclinação $=0,2219: 0,2111$ )

$-0,0099+0,1791 \mathrm{x}$

$\left(R^{2}=0,9992 ; \mathrm{F}=16745,13 ; \mathrm{LC}\right.$ intercepto $=-0,0019$ a $-0,01785 ;$ LC inclinação $=0,1821$ a 0,1761 )

A diferença entre os coeficientes angulares (inclinações) de 
ambas as Equações mostrou ser significativa $\left(t_{\text {cal. }}=3,438>t_{0,01(2), 26}\right.$ $\left.=2,778>t_{0,05(2), 26}=2,055\right)$, da mesma forma que a diferença entre as suas elevações $\left(t_{\text {cal. }}=9,082>t_{0,01(2), 27}=2,770>t_{0,05(2), 27}=2,051\right)$. A análise dos resíduos de regressão, realizada pelo teste de DurbinWatson não detectou autocorrelação nos dois casos ( $\mathrm{dw}_{\text {calculado }} 2,3047$ e 2,5975 (para 2,0 e 1,0 mL de reagente, respectivamente) $>\left(\mathrm{dw}_{\text {inferior }}\right.$ $1,08 \mathrm{e} \mathrm{dw}_{\text {superior }} 1,36(\mathrm{n}=15 ; \alpha=0,05)$.

A adiçãâ de 2,0 mL do reagente de Folin-Ciocalteu provocou ainda um efeito hipercrômico e um pequeno deslocamento batocrômico do $\lambda_{\text {máx }}$ obtidos com apenas $1,0 \mathrm{~mL}$ do reagente, os quais se mantiveram constantes quando o volume de reagente foi aumentado para 3,0 $\mathrm{mL}$. Dessa forma, o conjunto de resultados justifica a escolha do volume de 2,0 mL de reagente de Folin-Ciocalteu. O volume de 1,0 mL é preconizado no Método Geral de determinação de taninos $^{6}$ e em monografias específicas de várias Farmacopéias ${ }^{9,10}$.

O tipo e as quantidades de caseína foram definidos a partir dos resultados comparativos e do seu comportamento frente à rutina adicionada no meio. De modo geral, pode-se afirmar que a variabilidade experimental está associada ao tipo e a quantidade de caseína utilizada, principalmente no caso da caseína purificada (Figura 1). Para a caseína CGT, a falta de precisão intermediária somente foi observada em concentrações superiores a $600 \mathrm{mg}$ (Figura 2); no entanto, para a caseína purificada, este fato foi constatado para concentrações próximas a $100 \mathrm{mg}$. Da mesma forma, constatou-se certa dificuldade em obter dispersões homogêneas com quantidades acima de $400 \mathrm{mg}$ de caseína, principalmente com a caseína purificada originando resultados errôneos.

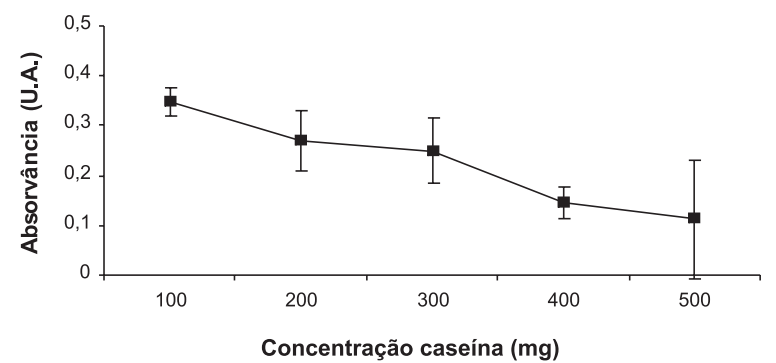

Figura 1. Valores de absorvância da fração residual da solução extrativa de Psidium guajava em função da concentração de caseína purificada. Os resultados representam os valores obtidos em triplicata em 3 dias consecutivos de análise

Em termos de precisão intermediária, os melhores resultados foram obtidos para uma concentração de, no máximo, $600 \mathrm{mg}$ de caseína CGT (Figura 2), fato pelo qual esse valor foi tomado como ponto de partida para definição da quantidade de caseína CGT a ser utilizada.

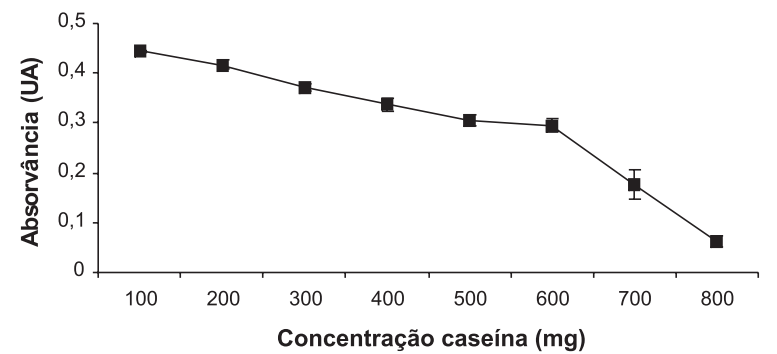

Figura 2. Valores de absorvância da fração residual da solução extrativa de Psidium guajava em função da concentração de caseína grau técnico. Os resultados representam os valores obtidos em triplicata em 3 dias consecutivos de análise

No que concerne à maior capacidade tanante e aos resultados errôneos decorrentes da dispersão da caseína, alguns trabalhos anteriores permitem explicar tanto um quanto o outro. O processo de purificação da caseína por desfosforilação afeta negativamente a coesão estrutural e a capacidade de formação de estruturas micelares, originalmente observadas na caseína bruta. Como consequiência, há um aumento da superfície reacional e uma maior capacidade de complexar taninos, porém, à custa de um aumento da hidrofobia da superfície ${ }^{13,14}$. Em caseínas brutas, as propriedades de superfície são influenciadas pelas $\kappa$ - e $\alpha_{\mathrm{s}}$-caseínas presentes na superfície das micelas ${ }^{14}$. Esta característica se perde na caseína purificada. Logo, o aumento na hidrofobia compromete a obtenção de dispersões homogeneamente ativas. Os resultados para os testes de repetibilidade e precisão intermediária estão contidos na Tabela 1 .

Tabela 1. Resultados obtidos para os parâmetros de reprodutibilidade e repetibilidade do método de determinação do teor de taninos totais de Psidium guajava

\begin{tabular}{lcc}
\hline & $\begin{array}{c}\text { REPRODUTIBILIDADE } \\
\text { PT (UA) }\end{array}$ & FNT (UA) \\
\hline Primeiro dia & 0,583 & 0,351 \\
Segundo dia & 0,574 & 0,334 \\
Terceiro dia & 0,580 & 0,326 \\
Média & 0,579 & 0,337 \\
Desvio padrão & 0,005 & 0,012 \\
CV $(\%)$ & 0,82 & 3,71 \\
\hline & REPETIBILIDADE \\
\hline Média & 0,617 & 0,359 \\
Desvio padrão & 0,004 & 0,005 \\
CV $(\%)$ & 0,65 & 1,40 \\
\hline
\end{tabular}

PT = Polifenóis totais; FNT = Fração não-tanante

Os resultados para repetibilidade e precisão intermediária foram inferiores ao limite de $5 \%$, preconizado para matrizes complexas, como drogas vegetais ${ }^{15}$.

Tomando como ponto de partida uma quantidade de $400 \mathrm{mg}$ de caseína $^{16}$, uma tomada de amostra de $0,5 \mathrm{~g}$ de material vegetal, 2 $\mathrm{mL}$ do reagente de Folin-Ciocalteu e leitura em $760 \mathrm{~nm}, 30 \mathrm{~min}$ após adição do reagente, os valores de absorvância obtidos (em torno de 0,36 ) foram diferentes daqueles obtidos quando da utilização de $100 \mathrm{mg}$ de pó-de-pele ${ }^{6}$. A utilização de $100 \mathrm{mg}$ de pó-depele levou à complexação quase total dos polifenóis presentes, resultando em uma fração não-tanante próxima de zero (0,094 U.A.).

O comportamento observado com o uso do pó-de-pele sugere fortemente uma falta de especificidade no método oficial. Sendo o método baseado na complexação com caseína, semelhante quanto ao princípio físico-químico de adsorção, na segunda parte do trabalho se deu ênfase ao estudo da especificidade de ambos os métodos.

A análise por UV da fração não-tanante mostrou uma extensão da complexação dos polifenóis do meio com 100 mg de pó-de-pele comparável àquela obtida com $800 \mathrm{mg}$ de caseína CGT ou $500 \mathrm{mg}$ caseína purificada (Figuras 1 e 2). Na faixa de 400 a $600 \mathrm{mg}$ de caseína CGT, a absorvância apresentou uma fase de relativa estabilização, em oposição ao observado para concentrações de caseína superiores a $600 \mathrm{mg}$, quando os valores de absorvância diminuíram e a variabilidade experimental aumentou.

A zona de estabilização observada para concentrações de 400 a 600 mg de caseína CGT (Figura 2) poderia, equivocadamente, ser atribuída a uma total complexação dos taninos, que precederia a complexação de outros polifenóis, de modo similar ao relatado para Maytenus ilicifolia ${ }^{16}$. Em face dessa afirmativa, foram adicionadas no presente trabalho quantidades acima de $600 \mathrm{mg}$ de caseína CGT ao extrato aquoso de Psidium guajava. Isto permitiu observar um decréscimo paulatino da absorvância, até atingir valores próximos de zero, o que poderia ser o resultado da complexação de outros 
polifenóis presentes no extrato vegetal.

Para comprovação desse pressuposto $0,2 \mathrm{~g}$ de rutina foram adicionados a $1 \mathrm{~L}$ do extrato vegetal e as análises com 400 e $600 \mathrm{mg}$ de caseína foram repetidas. A adição de rutina resultou em um aumento de 0,139 U.A. na absorvância, o qual foi reduzido para 0,100 U.A. quando utilizou-se $400 \mathrm{mg}$ de caseína CGT. Com 600 mg de caseína esse aumento desaparece completamente. Esses resultados sugerem que com a utilização de $600 \mathrm{mg}$ de caseína CGT já ocorre a retirada de taninos e de rutina do meio reacional.

Uma segunda forma de verificar o pressuposto de uma complexação dos flavonóides por parte da caseína foi utilizar a técnica de CLAEPDA. Para fins de comparação foi obtido o cromatograma de uma mistura contendo ácido gálico (monômero de tanino hidrolisável), pirogalol, catequina (monômero de tanino condensado) e rutina e os respectivos espectros no ultravioleta (Figura 3).

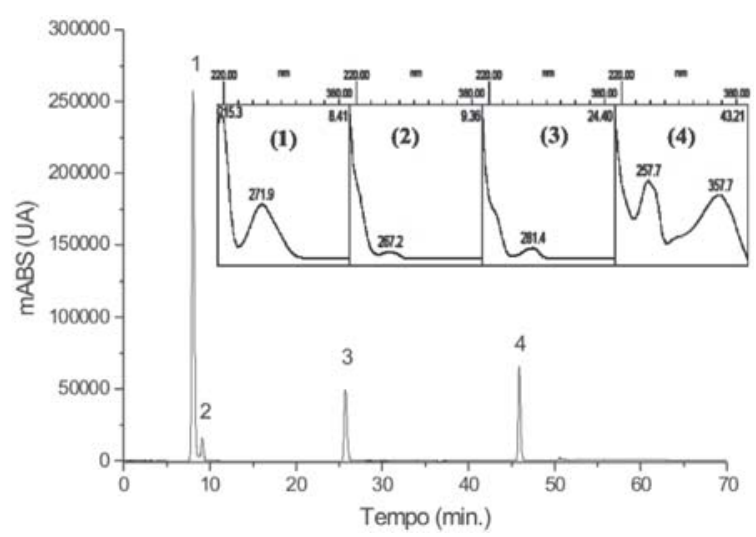

Figura 3. Cromatograma obtido para mistura de (1) ácido gálico, (2) pirogalol, (3) catequina e (4) rutina, acompanhado dos respectivos espectros no UV. Detecção em $280 \mathrm{~nm}$

A presença dessas substâncias no extrato vegetal foi analisada e os espectros no UV, relativos a picos de igual tempo de retenção, são mostrados na Figura 4.

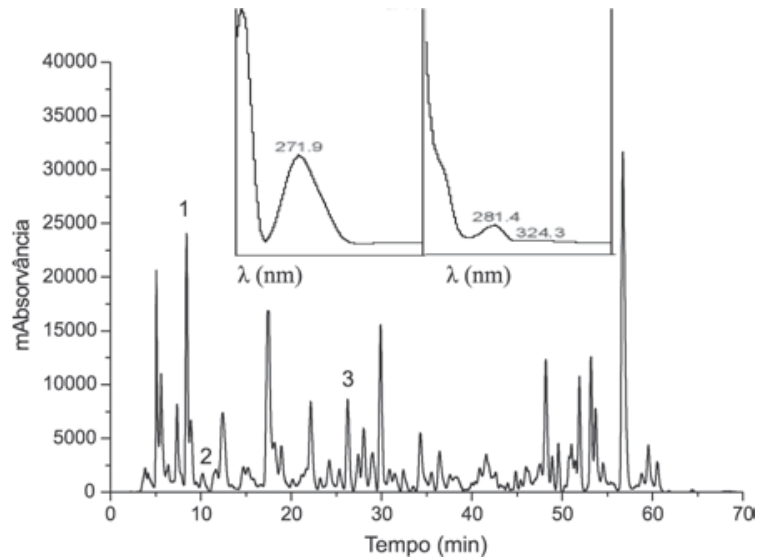

Figura 4. Cromatograma obtido para a solução extrativa de P. guajava $L$.: (1) ácido gálico; (3) catequina, acompanhados dos respectivos espectros no UV. Detecção em $280 \mathrm{~nm}$

A comparação dos cromatogramas e espectros no UV, contidos nas Figuras 3 e 4, permite concluir que o ácido gálico e a catequina estão presentes no extrato de Psidium guajava. As presenças de pirogalol (substância 2 - Figura 3) e de rutina (substância 4 - Figura 3) não puderam ser confirmadas de maneira inequívoca.

Mudando-se o comprimento de onda de detecção para $352 \mathrm{~nm}$ foi possível uma melhor detecção da fração flavonoídica presente no extrato vegetal (Figura 5).

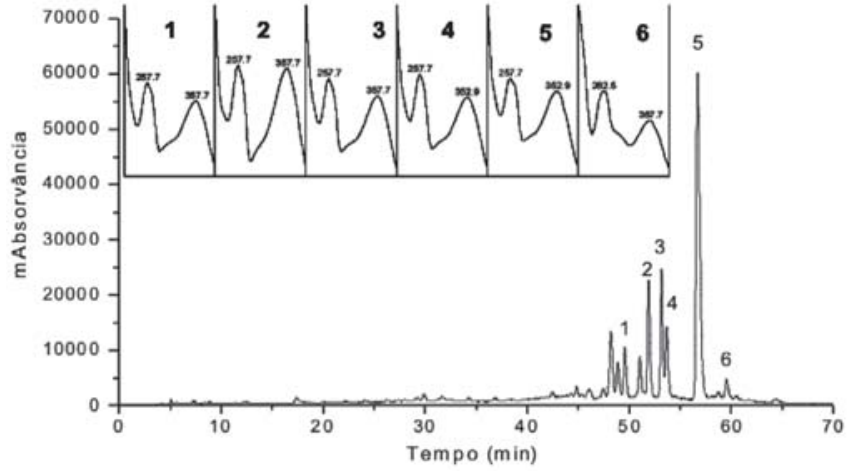

Figura 5. Cromatograma obtido para a solução extrativa de $\mathrm{P}$. guajava. Acompanham os espectros obtidos no UV para os picos 1, 2, 3, 4, 5, 6. Detecção em $352 \mathrm{~nm}$

A julgar pelos tempos de retenção e pelas duas bandas de absorção máxima em torno de 257 e $357 \mathrm{~nm}$, com um ombro próximo de $300 \mathrm{~nm}$ nos picos 1 a 5 (Figura 5), os espectros de UV identificam estruturas com dois cromóforos aromáticos conjugados, que são típicos de flavonóides e superponíveis aos observados para derivados da quercetina, como a rutina (Figura 3). O pico 6 apresenta máximos de absorções diferentes (262,5; 357,7 e aprox. $295 \mathrm{~nm})$, contudo, mantendo um perfil de absorção típico de flavonóides.

As análises dos cromatogramas obtidos por CLAE-PDA mostram claramente que há alterações na composição do extrato vegetal, quando da utilização de $400 \mathrm{mg}$ de caseína como agente complexante, independente da detecção realizada em 280 ou 352 nm (Figuras 6a e b). Contudo, cabe aqui observar que, por necessidade analítica, as concentrações das amostras analisadas por CLAE
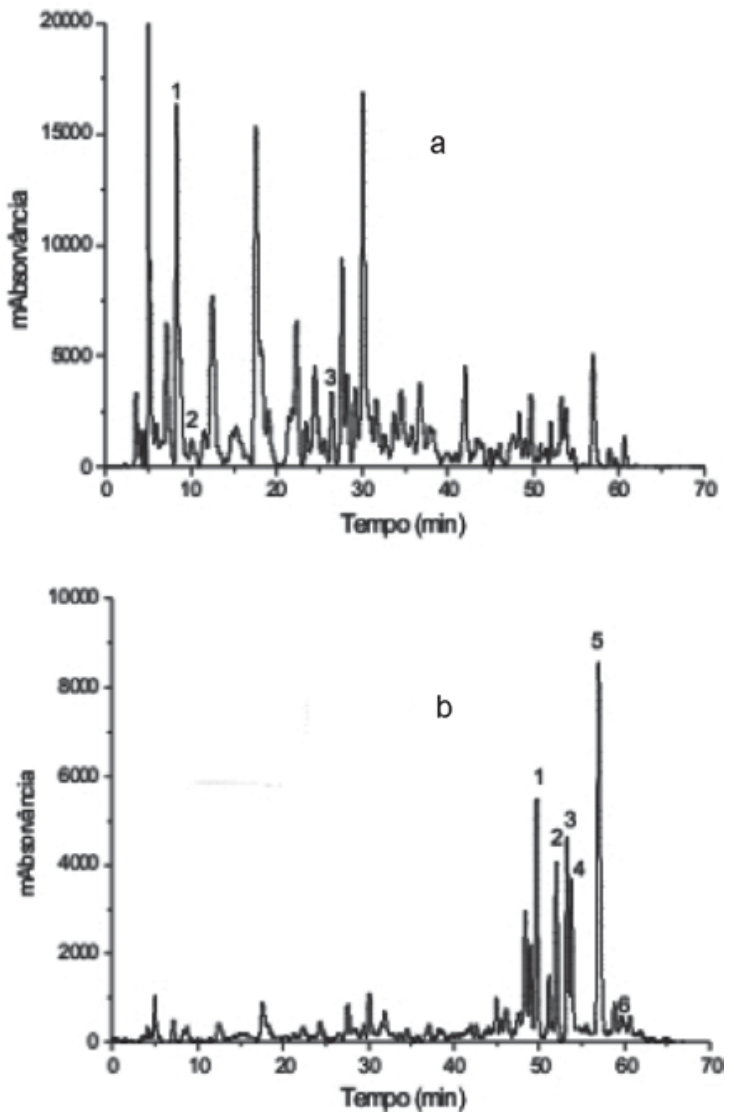

Figura 6. Cromatogramas da solução extrativa, obtidos após tratamento com 400 mg de caseína: a - detecção em $280 \mathrm{~nm}$; b-detecção em $352 \mathrm{~nm}$ 
foram quatro vezes maiores que as analisadas por UV.

Para restabelecer a mesma proporção extrato vegetal:caseína utilizada no método espectrofotométrico, a quantidade da proteína foi aumentada em quatro vezes, para $1600 \mathrm{mg}$ (Figuras 7a e b).
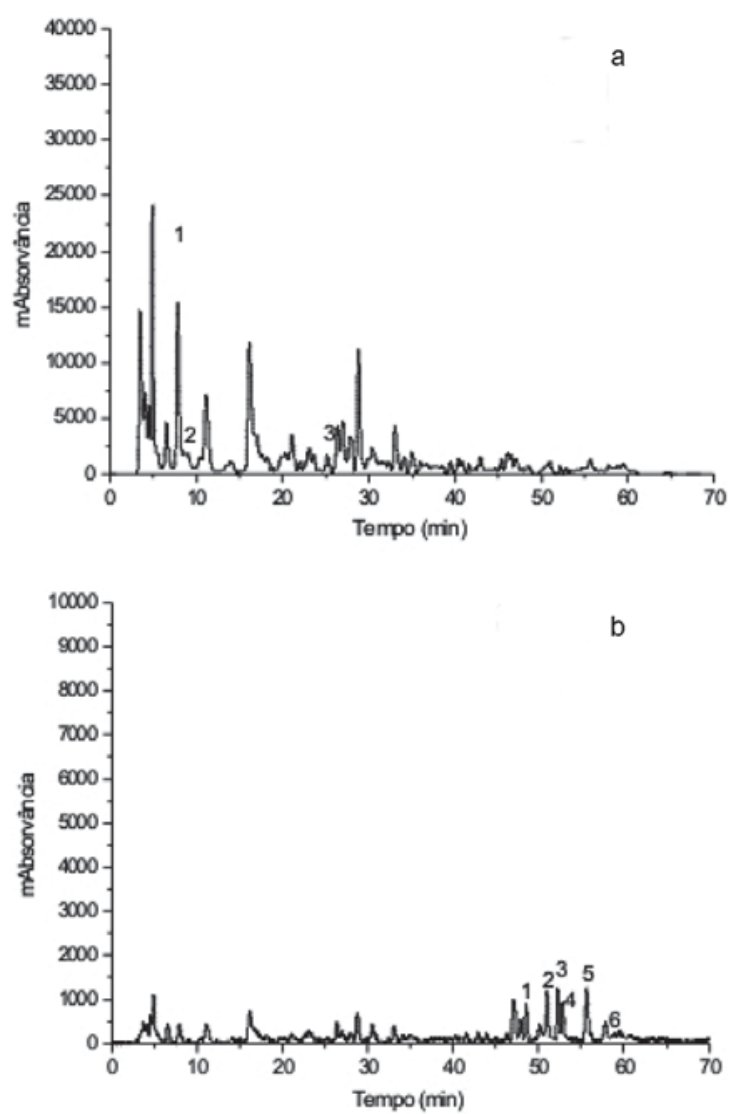

Figura 7. Cromatogramas da solução extrativa, obtidos após tratamento com 1600 mg de caseína. a - detecção em $280 \mathrm{~nm}$; b - detecção em $352 \mathrm{~nm}$

Dessa maneira fica evidente que a composição do extrato vegetal detectada a $280 \mathrm{~nm}$ (onde catequina e ácido gálico aparecem) foi claramente modificada pela adição de $1600 \mathrm{mg}$ de caseína. Ainda mais, a detecção em $352 \mathrm{~nm}$ mostra que nesse comprimento de onda, quando nem ácido gálico nem catequina são detectados e sim basicamente os flavonóides, a composição do extrato também foi claramente alterada.
A comparação deste fato com o uso de $100 \mathrm{mg}$ de pó-de-pele, também foi realizada de forma similar (Figuras $8 \mathrm{a}$ e b).

Nesse sentido as análises por CLAE-PDA confirmam a hipótese levantada por ocasião das análises por ultravioleta, ou seja, que tanto o pó-de-pele quanto a caseína são capazes de complexar os flavonóides do meio, fato que compromete a especificidade de ambos os métodos (Tabela 2). Contudo, merece especial atenção o fato da eficiência de retirada dos flavonóides ser mais acentuada com caseína que com $100 \mathrm{mg}$ de pó-de-pele, o que não condiz plenamente com o observado no método espectrofotométrico. Da mesma forma, o ácido gálico não demonstrou ser susceptível à complexação com caseína
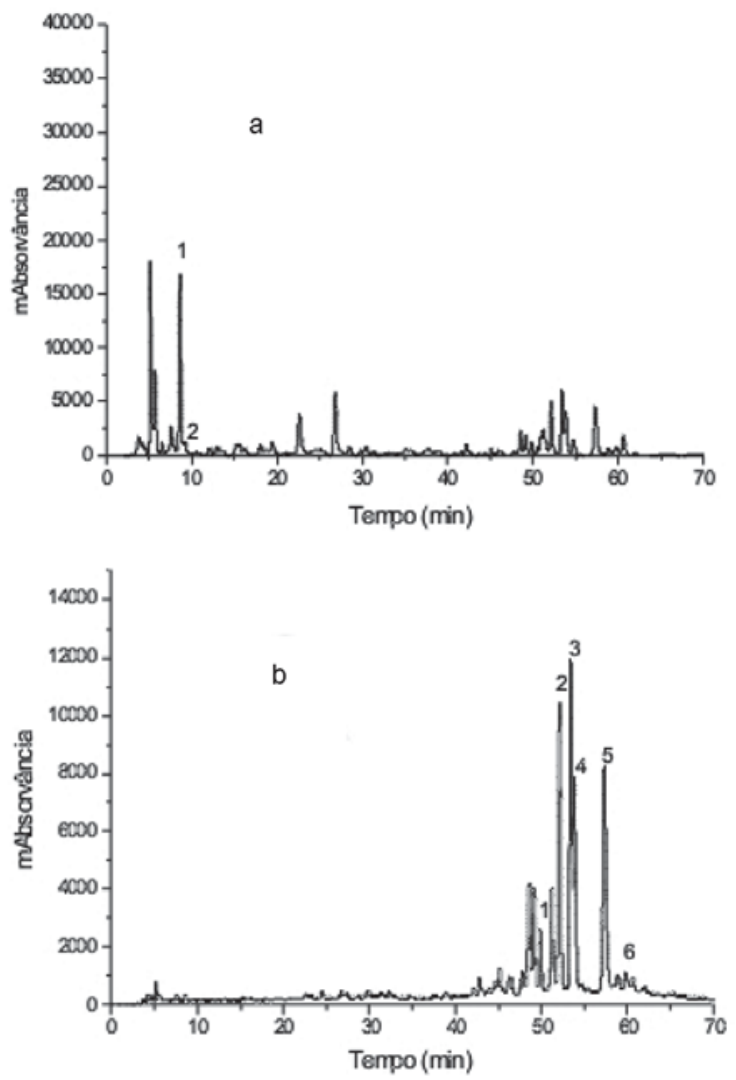

Figura 8. Cromatogramas da solução extrativa, obtidos após tratamento com $100 \mathrm{mg}$ de pó-de-pele. $a$ - deteç̧ão em $280 \mathrm{~nm}$; $b$ - deteç̧ão em $352 \mathrm{~nm}$

Tabela 2. Variação no perfil de flavonóides por CLAE-PDA da solução extrativa de Psidium guajava, utilizando caseína e pó-de-pele

\begin{tabular}{|c|c|c|c|c|c|c|}
\hline \multirow[t]{2}{*}{ DetecçãoAmostras } & \multicolumn{6}{|c|}{$352 \mathrm{~nm}$} \\
\hline & $\begin{array}{l}\text { Pico } 1 \\
\text { CV\% }\end{array}$ & $\begin{array}{l}\text { Pico } 2 \\
\text { CV\% }\end{array}$ & $\begin{array}{l}\text { Pico } 3 \\
\text { CV\% }\end{array}$ & $\begin{array}{c}\text { Pico } 4 \\
\text { CV\% }\end{array}$ & $\begin{array}{l}\text { Pico } 5 \\
\text { CV\% }\end{array}$ & $\begin{array}{l}\text { Pico } 6 \\
\text { CV\% }\end{array}$ \\
\hline \multirow[t]{2}{*}{$\mathrm{SE}$} & 211259,67 & 484263 & 498337 & 304879 & 1829781 & 104888 \\
\hline & 4,64 & 2,87 & 2,84 & 4,95 & 2,19 & 3,19 \\
\hline \multirow{2}{*}{$\mathrm{SE}+100$ mg de caseína } & 145489,33 & 200359,33 & 210617,67 & 146976,67 & 822999 & 34539,67 \\
\hline & 0,86 & 1,26 & 0,34 & 0,90 & 0,32 & 0,46 \\
\hline \multirow[t]{2}{*}{$\mathrm{SE}+400$ mg de caseína } & 95326,67 & 69407 & 76458 & 62348,33 & 206837 & 4395,33 \\
\hline & 1,56 & 3,86 & 0,55 & 1,34 & 0,38 & 5,10 \\
\hline \multirow[t]{2}{*}{$\mathrm{SE}+1600$ mg de caseína } & 15600 & 14914,67 & 18363,33 & 13389,33 & 26297,67 & - \\
\hline & 4,30 & 4,48 & 3,70 & 4,67 & 6,26 & \\
\hline \multirow[t]{2}{*}{$\mathrm{SE}+50 \mathrm{mg}$ de pó-de-pele } & 58271 & 198685,33 & 223450,33 & 150488 & 347445,3 & 21319,33 \\
\hline & 1,74 & 1,16 & 0,61 & 2,71 & 0,95 & 1,70 \\
\hline \multirow{2}{*}{$\mathrm{SE}+100$ mg de pó-de-pele } & 38769,67 & 174514,33 & 194412,67 & 135160,7 & 196593,3 & 11144,67 \\
\hline & 1,40 & 1,85 & 0,42 & 2,50 & 0,81 & 5,64 \\
\hline
\end{tabular}

Nota: SE solução extrativa; CV \%: coeficiente de variação percentual $(\mathrm{n}=3)$. 
ou pó-de-pele, o que também comprometeria seu uso como substância de referência na quantificação de taninos. De forma adicional, a análise dos dados por CLAE-PDA indica que tanto a caseína quanto o pó-de-pele têm uma afinidade maior por catequina e flavonóides que por ácido gálico (Figuras 4-8).

\section{CONCLUSÕES}

A aplicação do método de Folin-Ciocalteu, com etapa de adsorção com caseína, quando aplicado à determinação do teor de taninos totais de folhas de Psidium guajava implica parâmetros analíticos críticos. Considerando o tipo de polifenol analisado e a natureza do reagente evidenciou-se claramente a necessidade de estabelecer parâmetros como tempo de leitura, comprimento de onda e quantidade de reagente.

Além desses, o tipo de caseína mostrou ser uma variável analítica importante. A julgar pelos resultados o processo de purificação melhora a capacidade de complexação da caseína, porém compromete a precisão, em face de sua dificuldade de formar dispersões homogêneas. A análise das misturas do extrato aquoso e rutina mostrou que a caseína CGT complexou de forma indiferente tanto flavonóides quanto catequina e ácido gálico. Resultados semelhantes foram obtidos quando a caseína foi substituída por pó-de-pele. Esses resultados foram evidenciados através de método espectrofotométrico e por CLAE. Os dados obtidos comprometem a especificidade e qualquer tentativa de validação do método para Psidium guajava. No entanto, os resultados aqui obtidos não podem ser trans- postos sem mais ensaios para outras drogas vegetais, tendo em vista que o processo de complexação está relacionado com as características das proteínas e polifenóis presentes no meio.

\section{REFERÊNCIAS}

1. Folin, O.; Macallum, A. B.; J. Biol. Chem. 1912, 265.

2. Folin, O.; Denis, W.; J. Biol. Chem. 1912, 12, 239; Folin, O.; Ciocalteau, V.; J. Biol. Chem. 1927, 73, 627.

3. Bruneton, J.; Farmacognosia- Fitoquímica plantas Medicinales, $2^{\mathrm{a}}$ ed., Acríbia: Zaragoza, 2001.

4. Costa, A. F.; Farmacognosia, $5^{\text {a }}$ ed., Calouste Gulbenkian: Lisboa, 1994.

5. Santos, S. C.; Mello, J. C. P. Em Taninos; Simões, C. M. O.; Schenkel, E. P.; Gosmann, G.; Mello, J. C. P.; Mentz, L. A.; Petrovick, P. R., eds.; UFRGS: Porto Alegre, 2003, cap. 24.

6. European Pharmacopoeia; $4^{\text {th }}$ ed., EDQM: France, 2002.

7. Draper, N. R.; Smith, H.; Applied Regression Analysis, $3^{\text {rd }}$ ed.,Wiley: New York, 1998.

8. Zar, J. H.; Biostatistical Analysis, $4^{\text {th }}$ ed., Prentice Hall: New Jersey, 1999.

9. British Pharmacopoeia; Stationary Office: London, 1999.

10. Deutsches Arzneibuch, 3. Aufl., Deutscher Apotheker: Stuttgart, 1998.

11. Farmacopéia Brasileira; 4⿳a ed., Atheneu: São Paulo, 1988.

12. Martins, A. G.; Dissertação de Mestrado, Universidade Federal do Rio Grande do Sul, Brasil, 1999.

13. Jöbstl, E.; O'Connel, J.; Faircolough, J.; Williamson, M.; Biomacromolecules 2004, 5, 942.

14. Luck, G.; Liao, H.; Murray, N. J.; Grimmer, H. R.; Warminski, E. E.; Williamson, M. P.; Lilley, T. H.; Haslam, E.; Phytochemistry 1994, 37, 357.

15. Hefendehl, F. W.; Seminar der Arbeitsgruppe "Parmazeustische Analytik", Graz: Österreiche Pharmazeutische Gesellschaft, 1985.

16. Soares, L. A. L.; Tese de Doutorado, Universidade Federal do Rio Grande do Sul, Brasil, 2002. 